\title{
Nodular fasciitis of the zygoma: A case report
}

\author{
Tarren Vyas MD ${ }^{1}$, Martin J Bullock MD FRCP ${ }^{2}$, Robert D Hart MD FRCSC ${ }^{1}$, Jonathan R Trites MD FRCSC ${ }^{1}$, \\ S Mark Taylor MD FRCSC FACS ${ }^{1}$
}

\begin{abstract}
T Vyas, MJ Bullock, RD Hart, JR Trites, SM Taylor. Nodular fasciitis of the zygoma: A case report. Can J Plast Surg 2008;16(4):241-243.

Nodular fasciitis (NF), a benign proliferation of fibroblasts, commonly presents as a solitary, well-circumscribed, rapidly growing soft tissue mass. It is most commonly located in the upper extremities, particularly on the volar aspect of the elbow, and on the chest and trunk. In adults, NF is rarely found in the head and neck region. Although benign, it can often be confused with a more malignant process and therefore must be properly diagnosed histologically. The cause of NF is unknown but an association with trauma may be present. Treatment is most commonly by local surgical excision, and recurrence is rare. A case of NF over the zygoma in a 60-year-old man not associated with trauma is presented.
\end{abstract}

Key Words: Benign; Face; Mass; Nodular fasciitis; Zygoma

\section{Fasciite nodulaire affectant le zygoma : Rapport de cas}

La fasciite nodulaire (FN), une prolifération bénigne des fibroblastes, se présente souvent sous la forme d'une masse isolée, bien circonscrite, croissant rapidement dans des tissus mous. On l'observe dans la plupart des cas au niveau des membres supérieurs, particulièrement à la face antérieure du coude, à la poitrine et au torse. Chez les adultes, la FN s'observe rarement au niveau de la tête et du cou. Bien que bénigne, elle peut souvent être confondue avec une anomalie plus maligne et, par conséquent, doit être adéquatement diagnostiquée sur le plan histologique. La cause de la FN est inconnue, mais un lien avec un traumatisme s'observe parfois. Le traitement se fait le plus souvent par exérèse chirurgicale locale et les récurrences sont rares. On décrit ici un cas de FN affectant le zygoma chez un homme de 60 ans; dans ce cas précis, le phénomène n'a pas été relié à aucun traumatisme.
Cirst described by Konwaler et al in 1955 (1), nodular fasci$\mathrm{C}_{\text {itis }}(\mathrm{NF})$ is also known as pseudosarcomatous fasciitis, pseudosarcomatous fibromatosis and infiltrative fasciitis. It is a reactive, self-limited, proliferation of fibroblasts most commonly found in the subcutaneous tissue. It commonly presents as a solitary, well-circumscribed, rapidly growing soft tissue mass that may be painful or tender. NF is a benign lesion but can often be confused with myofibromatosis or a sarcoma due to its rapid rate of growth, rich cellularity and mitotic activity $(2,3)$. It is important, therefore, to distinguish the lesion from a more aggressive condition.

NF that occurs in otherwise healthy individuals usually presents with a history of rapid growth, and is commonly found in the upper extremities and on the chest and trunk. Although a common site in the pediatric population, it is more rarely found in the head and neck region in the adult population.

We present a case of NF in a 60 -year-old man who presented with a localized mass over his right zygoma.

\section{CASE PRESENTATION}

A 60-year-old Caucasian man first noticed extensive swelling bilaterally over the inferior orbital rims while vacationing in Florida. He attributed this to his allergies and took diphenhydramine, which did appear to decrease the swelling. The remainder of the swelling slowly resolved over the following two weeks but a fleshy, painless mass remained over the area of the right zygoma. He denied any history of trauma to the region or any previous radiation to the head or neck.
His medical history was significant for a similar lesion removed from his left arm over 10 years previously. The pathology from this surgery remains unavailable. The patient also had a previous septoplasty and a previous nasal fracture.

Upon returning from Florida, he presented to his local hospital. Computed tomography revealed a $2 \mathrm{~cm} \times 1.3 \mathrm{~cm}$ subcutaneous lesion abutting the right zygoma with mild erosion of the outer cortex. A fine needle aspiration was performed and showed multiple spindle and stellate cells. This was suggestive of NF but a stromal reaction to some other underlying pathological process, such as a true soft tissue tumour, could not be completely excluded. Therefore, an open biopsy was recommended. The open biopsy was found to be consistent with NF with no evidence of malignancy. The patient developed a minor wound infection after the biopsy and this was successfully treated with oral antibiotics.

The patient was referred to the Queen Elizabeth II Health Sciences Centre (Halifax, Nova Scotia) for further management. Physical examination revealed a firm, nontender, immobile mass over his right zygoma. The mass measured $3 \mathrm{~cm} \times 2 \mathrm{~cm}$ and was fixed to the overlying scar from the previous biopsy.

The patient consented to definitive resection of the mass. A transfacial approach through the previous biopsy site was planned with excision of the involved facial skin. A $6 \mathrm{~cm}$ incision was fashioned in the direction of the relaxed skin tension lines. A full-thickness excision of skin and soft tissue down to the outer cortex of the zygoma was performed. Some

\footnotetext{
${ }^{1}$ Division of Otolaryngology - Head and Neck Surgery; ${ }^{2}$ Department of Pathology, Dalhousie University, Halifax, Nova Scotia
}

Correspondence: Dr Tarren Vyas, 3462 St Andrews Avenue, Halifax, Nova Scotia B3L 3Y1. Telephone 902-453-4058,

fax902-429-9184, e-mail tvyas@dal.ca 


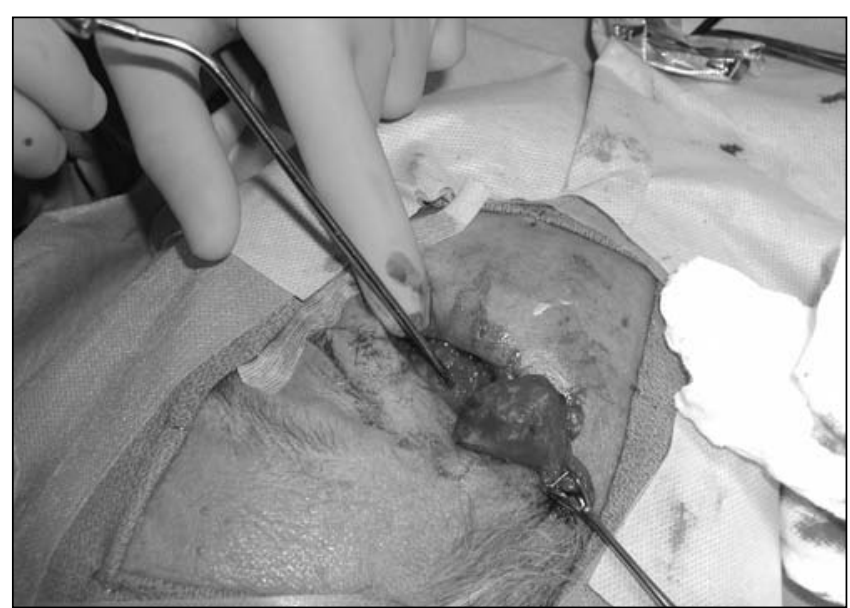

Figure 1) Resection of mass from area over the right zygoma. The tip of Fraser catheter shows malar prominence

scalloping of the outer cortex was noted at the deep margin and a superficial margin of bone was removed deep to the resection (Figure 1). Gelfoam was placed into the bone defect and the remaining soft tissue was mobilized and closed.

Gross examination of the pathological specimen showed a well-circumscribed, $3 \mathrm{~cm}$ tan-white mass centred in the subcutis. Microscopically, it consisted of intersecting fascicles of bland spindle cells within a focally mixed stroma. Also within the stroma were aggregates of dense, wavy 'keloidal'-type collagen and many extravasated red blood cells (Figure 2). Microscopically, the zygoma was not involved. These findings were consistent with a dermal NF. The mass extended from the deep dermis into the subcutis where it focally involved the deep margin. The cortex of the zygoma was not involved.

The patient's postoperative course was uneventful and a three-month follow-up showed that his scar was healing well. There was no evidence of facial nerve paresis and no residual facial contour deformity.

\section{DISCUSSION}

To date, there have been limited reports of such lesions over the zygoma. To our knowledge, only three other cases of NF specifically over the zygomatic area have been reported (4-6). Two of these are reported outside the English literature $(4,5)$ and all three are associated with trauma to the area. In addition, one such case was in a child (4). There has been no known prior report of a case of NF over the zygoma in an adult not associated with previous trauma.

NF can occur almost anywhere on the body; however, the most common location in the adult population is in the upper extremities (39\% to $54 \%$ ), especially on the volar aspect of the elbow. They can also be found on the trunk (15\% to 20\%) and the lower extremities (16\% to $18 \%$ ). NF is located in the head and neck only in $7 \%$ to $20 \%$ of cases (3). In children, however, the head and neck region is the most common site. Approximately $10 \%$ of all lesions are found in children (7). In addition, it is more commonly found in those in the third through fifth decades of life; only $10 \%$ to $20 \%$ are found in those over 50 years of age $(3,8)$.

NF usually appears as a solitary mass and may be occasionally tender on palpation. It usually ranges from $1 \mathrm{~cm}$ to $3 \mathrm{~cm}$ in greatest diameter. The cause is unknown but has often been linked to local injury or trauma. In the literature, $10 \%$ to $15 \%$

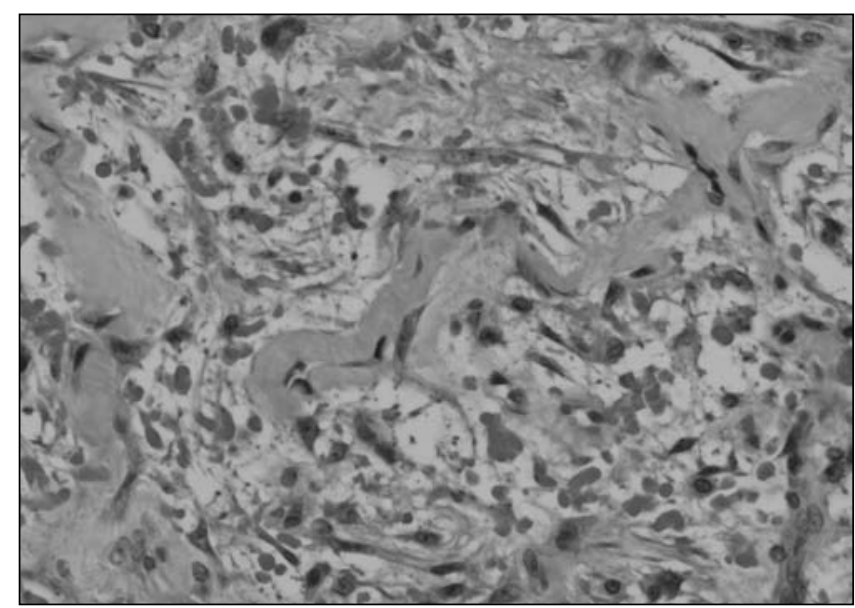

Figure 2) Photograph of nodular fasciitis, showing loosely organized spindle cells with scattered extravasated red blood cells and dense keloidal collagen (hematoxylin and eosin stain, original magnification $\times 400$ )

of cases have been found to be associated with trauma $(2,7,9)$; this was not the case in our patient.

Proper diagnosis requires histological confirmation. NF typically shows well-circumscribed, unencapsulated nodules composed of spindle cells. Dermal NF is a variant of NF that is commonly found in the head and neck region. The high prevalence of this variant is thought to be due to facial muscles being attached to the overlying skin by the superficial musculoaponeurotic system.

Treatment is most commonly by local surgical excision. Although the deep margins were close in our case, the majority of residual tumour will spontaneously regress $(10,11)$. Generally, if recurrence does occur after excision, incomplete resection should be suspected but a malignant process should be reconsidered (12-14). This is especially important in those that do not recur shortly after excision because those that recur later are more likely to be associated with another process. Occasionally, lesions may spontaneously regress, and if the diagnosis of NF is confirmed, no further treatment is necessary.

\section{SUMMARY}

$\mathrm{NF}$ is an uncommon benign proliferation of fibrous tissue. It is important to distinguish it from a malignant process because NF can be successfully treated with complete local excision. Presentation in the maxillofacial region, especially in the older adult population, is rare and as such limited cases are reported.

\section{REFERENCES}

1. Konwaler BE, Keasbey L, Kaplan L. Subcutaneous pseudosarcomatous fibromatosis (fasciitis). Am J Clin Pathol 1955;25:241-52.

2. Han W, Hu Q, Yang X, Wang Z, Huang X. Nodular fasciitis in the orofacial region. Int J Oral Maxillofac Surg 2006;35:924-7.

3. Kijima H, Okada K, Ito H, Shimada Y, Nanjo H, Itoi E. Nodular fasciitis of the finger. Skeletal Radiol 2005;34:121-3.

4. Acocella G, Nardi N, Acocella A. [Nodular fasciitis in the zygomatic area. Case report and review of the literature]. Minerva Stomatol 2002;51:103-6.

5. Hermans R. [Nodular fasciitis: A case at the level of the zygomatic arch]. J Belge Radiol 1990;73:493-5.

6. Yoskovitch A, Hier M, Bégin LR, Black M. Pathologic quiz case 1: Nodular fasciitis (NF). Arch Otolaryngol Head Neck Surg 1998;124:926-8. 
7. Zuber TJ, Finley JL. Nodular fasciitis. South Med J 1994;87:842-4.

8. Martinez-Blanco M, Bagan JV, Alba JR, Basterra J. Maxillofacial nodular fasciitis: A report of 3 cases. J Oral Maxillofac Surg 2002;60:1211-4.

9. de Paula SA, Cruz AA, de Alencar VM, Akaishi PM, Chahud F. Nodular fasciitis presenting as a large mass in the upper eyelid. Ophthal Plast Reconstr Surg 2006;22:494-5.

10. Bau JL, Ly JQ, Lusk JD. Quiz case. Nodular fasciitis. Eur J Radiol 2003;47:54-6.
11. Haddad AJ, Avon SL, Clokie CM, Sandor GK. Nodular fasciitis in the oral cavity. J Can Dent Assoc 2001;67:664-7.

12. Huang CD, Lin YH, Lee FP. Postauricular nodular fasciitis. Otolaryngol Head Neck Surg 2007;137:164-5.

13. Haas AF. Nodular fasciitis of the forehead. Dermatol Surg 1999;25:140-2.

14. Nishi SP, Brey NV, Sanchez RL. Dermal nodular fasciitis: Three case reports of the head and neck and literature review. J Cutan Pathol 2006;33:378-82. 